revista do ieb n 44 p. 159-172 fev 2007

\title{
Pós-Tudo: banimento e abandono no Grande Sertão
}

Ettore Finazzi-Agrò *

Resumo

No romance Grande sertão: veredas, o encontro com os catrumanos provoca, em Riobaldo, pensamentos em que se misturam piedade e medo. As suas considerações e o tratamento que ele vai reservar a eles enquanto Urutu-Branco chegam a delinear, para esses "homens de estranhoso aspecto", um quadro complexo e ambivalente de relações de força e de poder, ligando, num aparente paradoxo, aquela "raça diverseada distante" com o personagem de Zé Bebelo. 0 fio unindo esses dois extremos pode ser identificado num "estado de exceção" que, de forma especular, coloca na mesma situação de anomia, de exterioridade em relação à lei sertaneja, tanto o emblema da lógica política quanto as vítimas-algozes de uma biopolítica que o Poder inclui no seu discurso com o mesmo gesto com que as exclui.

\section{Palavras-chave}

catrumanos, Zé Bebelo, exceção, biopolítica, banimento.

* professor de Literatura da Universidade de Roma - "La Sapienza". 
revista do ieb n 44 p. 159-172 fev 2007

\title{
Post-everything: banishment and abandonment in the Grande Sertão
}

Ettore Finazzi-Agrò

\begin{abstract}
In the novel Grande sertão: veredas, the encounter with the catrumanos gives Riobaldo thoughts that blend compassion and fear. His considerations and the way he will treat them, as Urutu-Branco, outlines, to those "men of weird appearance", a complex and ambivalent picture of the relations of strength and power, connecting, in an apparent paradox, that "distant and diverse race" with the character of Zé Bebelo. The thread joining the two extremes can be identified in a "state of exception" that, in an mirrored image, places the political logic and the victims and agents of power in the same situation of anomy.
\end{abstract}

\section{Keywords}

catrumanos, Zé Bebelo, exception, biopolitics, banishment. 
Mit allen Augen sicht die Kreatur das Offene. Nur unsere Augen sind wie umgekehrt und ganz um sie gestellt als Fallen, rings um ihren freien Ausgang. Rainer M. Rilke, Die achte Elegie

0 homem, de fato, nunca coincide de modo algum com a vida nua do homem; nem com a vida nua dentro dele nem com algum outro estado ou propriedade, nem mesmo com a unicidade da sua pessoa física. Tão sagrado é o homem [...], quão pouco o são os seus estados, quão pouco o é a sua vida física, vulnerável pelos outros. 0 que, com efeito, a distingue essencialmente daquela dos animais e das plantas?

Walter Benjamin, Zur Kritik der Gewalt

Houve, e ainda há, na espécie humana muitos "sujeitos" que não são reconhecidos como sujeitos e recebem o mesmo tratamento do animal [...]. Aquilo que se chama confusamente animal, então o vivente enquanto tal e nada mais, não é um sujeito da lei e do direito. A oposição entre justo e injusto não faz algum sentido quanto a ele.

Jacques Derrida, Force de loi

Nos últimos anos, como todos nós bem sabemos, temos assistido a uma proliferação descontrolada de termos precedidos pelo prefixo pós - do pós-moderno ao pós-colonialismo, passando, obviamente, pela definição onicompreensiva e, de certo modo, conclusiva de "pós-história” (sem esquecer, evidentemente, a categoria do "pós-trágico" que contribuí, com outros, para colocar em pauta em relação à moderna cultura brasileira). Cada um deles tem (ou teve) o seu valor hermenêutico na época e em relação ao objeto a que é (ou foi) aplicado, mas, mais em geral, esse uso contundente e coincidente do mesmo prefixo leva fatalmente a nos interrogarmos sobre a própria natureza póstuma da nossa condição de leitores e intérpretes de fenômenos culturais e de discursos artísticos que habitam a modernidade ocidental.

Para além ou para aquém de qualquer revisão (muitas vezes justa) ou negação (às vezes injusta) dessas categorias teóricas ou dessas definições críticas, penso que a nossa relação com o texto de João Guimarães Rosa, sobretudo hoje, cinqüenta anos depois da publicação de Corpo de baile e Grande sertão: veredas, deveria, necessariamente, levar em conta o caráter inelutavelmente posterior e, ao mesmo tempo, ulterior de qualquer leitura que pretenda identificar significados ocultos no interior 
da escrita. Póstumo, nesse sentido, quer dizer fatalmente arbitrário e, concomitantemente, necessário - daquela necessidade que vem, justamente, da profundeza e espessura temporal em que se amontoam e chamam a nossa atenção as outras interpretações, as inúmeras vozes críticas, os muitos caminhos percorridos através e em volta da obra rosiana.

Chegamos depois de um fim, de fato: um fim ambíguo, aliás, e que não encerra um sentido, não delimita um território textual, mas que, isto sim, define (sem definir) aquela zona incerta e perigosa que se abre entre o sim e o não, entre a afirmação e a interrogação, entre a certeza e a dúvida. Considero, por isso, que, para continuar lendo a narrativa rosiana, devemos assumir a nossa condição póstuma, isto é, de-morar nessa zona incerta, habitar esse limiar que não separa nem junta, mas que deixa, a meu ver, balançar o discurso numa latência que nenhuma de-cisão ou corte pode tornar uni-forme ou uní-voco (também porque ele é, como se sabe, um discurso freqüentemente ubíquo, monológico e dialógico ao mesmo tempo). Estamos, com efeito, num depois sem garantias, que permite traçar percursos diferentes e até antinômicos dentro de uma dimensão que é, também ela, interrogativa e duvidosa - como o demonstra, por exemplo, a ausência, justamente, da palavra Fim em Grande sertão: veredas, substituída pela lemniscata, pelo símbolo matemático do infinito, ou a porosidade das fronteiras discursivas e textuais numa estória "difícil", "muito ruim para se contar e se ouvir", como é "Cara-de-bronze".

Esta situação de pós-tudo em que nos encontramos não pode todavia justificar qualquer leitura, tratando o texto de Rosa como se fosse apenas um palimpsesto sobre o qual escrever ou rabiscar à vontade; no qual gravar significados impróprios ou até descabidos, secundando a preocupação do leitor em vez de definir e mapear a ocupação real do espaço narrativo e significante por parte do autor. Penso, nessa perspectiva, que o respeito para e pelo texto (ou seja, etimologicamente, o olhar e o ser olhado por ele) nos deveria levar a defender as verdades intercaladas, a "patrulhar" os limiares, ou seja, aqueles contornos cinzentos, ou melhor, aquelas frestas que se entre-abrem no discurso do escritor - nos deveria levar, em suma, a vigiar (com o entêtement du guetteur, com a "teimosia do vigia", como sugeriu, justamente, Roland Barthes) aquelas encruzilhadas precárias em que conseguimos às vezes surpreender e nos "apoderar" de um sentido provisório. 0 caráter póstumo da nossa leitura poderia se espelhar, assim, na natureza movediça e continuamente ulterior da escrita de Guimarães Rosa, tornando a hermenêutica textual uma articulação ou um prolongamento (uma travessia inconclusa, talvez) do hermetismo próprio do texto. 
Existem, aliás, lugares dentro da obra do escritor mineiro que se apresentam como verdadeiras fendas do tecido narrativo, como estórias ou dimensões "en abîme" em que conseguimos entrever e apanhar por instantes o sentido integral do texto, o seu valor implícito e a sua intenção de dizer aquilo que não pode ser dito de modo explícito e que, justamente por isso, só pode ser inter-dito, ou seja, "dito entre", colocado no limiar entre a decisão e a demanda. Um deles pode, a meu ver, ser localizado no interior da fala cambaleante, do contar e recontar emaranhado de Riobaldo. 0 sinal de atenção, o alarme para a importância do evento contado é dado, no caso de que eu quero tratar aqui, pelo próprio autor:

Rir, o que se ria. De mesmo com as penúrias e descômodos, a gente carecia de achar os ases naquele povo de sujeitos, que viviam só por paciência de remedar coisas que nem conheciam. As criaturas.

Mas eu não ri. Ah, daí, não ri honesto nunca mais, em minha vida. ${ }^{1}$

0 que pode impedir, de modo definitivo, o riso (o "riso honesto", certo, mas o riso desonesto é apenas o deboche; é um esgar, uma grimace, como diriam os franceses, remetendo para uma situação de desassossego, de gozo inquieto ou perverso)? 0 que pode, enfim, tirar para sempre o sorriso e a alegria? Essa tristeza súbita e completa, essa mortalha de luto e desespero apartando Tatarana dos seus companheiros é algo que desperta a nossa atenção e nos encaminha para uma releitura atenta do contexto, ajudando-nos talvez a descobrir o fundo verdadeiro, histórico (ou talvez, pós-histórico), escondido nas dobras da estória, nos recantos ou, justamente, nas margens da ficção.

De fato, aquilo que acaba de acontecer é o aparecimento dos catrumanos: gente inesperada, vinda não se sabe de que lugar e de que tempo, que se depara na frente e à vista do bando de jagunços chefiados por Zé Bebelo. Estamos - como nos mostrou Willi Bolle ${ }^{2}$ - transviados no labirinto dos sertões, onde a viagem perdeu momentaneamente o seu alvo, e a reação de Riobaldo poderia ser apenas o fruto desse transtorno, dessa falta de perspectivas que o bando inteiro está vivendo. Mas ele su-

1 ROSA, João Guimarães. Grande sertão: veredas. 15. ed. Rio de Janeiro: José Olympio, 1982. p. 293. Doravante GS:V.

2 BOLLE, Willi. Grande sertão: cidades. Revista USP, São Paulo, n. 24, p. 80-93, dez.-fev. 1994/95. 
blinha, todavia, que a sua atitude e o seu modo de reagir àquele encontro é só dele:

Bobéia minha? Porque os companheiros, indo cuidando do seu ramerrão comum, nenhum não punha tento em dessas idéias. Então era só eu? Era. Eu, que estava mal-invocado por aqueles catrumanos do sertão. Do fundo do sertão. 0 sertão: o senhor sabe. ${ }^{3}$

Portanto, a postura diante da visão daquele punhado de miseráveis é absolutamente pessoal, apartando Riobaldo dos outros, sobretudo pelo fato dele o considerar logo um sinal de azar: "a hora tinha de ser o começo de muita aflição, eu pressentia"4. E a pergunta, neste ponto, é sobre os motivos de tanta perturbação, visto que, afinal, Riobaldo já vinha passando por muita violência e muitos apertos, já vinha assistindo a cenas de pobreza e de desamparo, e aquele povo faminto e maltrapilho não aparentava, no fundo, constituir uma exceção tão gritante dentro da geral miséria sertaneja.

A resposta poderia ser dada em vários níveis (político, social, histórico ou ético), mas eu acho que aqui estamos perto do núcleo trágico da obra, no centro do drama existencial montado por João Guimarães Rosa, ou seja, que o surgimento daqueles "homens de estranhoso aspecto" (a que se poderia associar a passagem sucessiva pelo povoado de Sucruiú, que já entra, porém, no período de "muita aflição" prenunciado por eles) é efetivamente uma espécie de limiar simbólico que dá acesso a uma dimensão abismal ou infernal, marcada pelo pacto, pelo combate no Paredão e pela morte de Diadorim. Sabe-se, aliás, que Rosa gostava de disseminar em sua escrita indícios ou "préavisos" : um modo de vaguear entre os tempos da narrativa, avançando e regredindo numa rede de fatos dispostos de forma con-torcida ou redobrada, nas idas e voltas do discurso. Mas a vista dos catrumanos, o seu puro existir, apresenta-se-nos como algo mais do que um simples aviso: eles são a fronteira, extrema ou anterior a tudo, que dá e nega o acesso a uma dimensão medonha e terrível; na sua "estúrdia" evidência, na sua aturdida bestialidade, eles são ao mesmo tempo as vítimas e os carrascos

$3 G S: V$, p. 295.

$4 G S: V$, p. 293-4.

5 SPERBER, Suzy F. Guimarães Rosa: signo e sentimento. São Paulo: Ática, 1982. p. 119-22. 
de um delito horrendo, que é histórico, é social, é político, é, enfim, humano - "demasiado humano", talvez.

De fato, Riobaldo junta-os, enquanto vítimas, numa compaixão infinita ("tanteei pena deles, grande pena"6), para depois cultivar uma sensação montante de medo, que se alastra até chegar a uma visão apocalíptica:

E de repente aqueles homens podiam ser montão, montoeira, aos milhares mís e centos milhentos, vinham se desentocando e formando, do brenhal, enchiam os caminhos todos, tomavam conta das cidades. [...] E pegavam as mulheres, e puxavam para as ruas, com pouco nem se tinha mais ruas, nem roupinhas de meninos, nem casas. Era preciso de mandar tocar depressa os sinos das igrejas, urgência implorando de Deus o socorro. ${ }^{7}$

0 pequeno grupo de catrumanos se torna multidão, na fantasia assustada de Tatarana, agentes, então, de um tumulto ${ }^{8}$ que não pode ser contido, de uma subversão infinita e sem confins, de um estado de exceção incontrolável, espalhando-se do fundo do sertão até as cidades, levando consigo e sendo levados por uma violência sem nome e sem norma que tudo destrói. Os poucos se tornam uma turba e a turba provoca um turbilhão (para usar uma sugestiva imagem de Michel Serres ${ }^{9}$ ), jogando o sujeito e o mundo numa situação de total anomia: é o Mal se expandindo em todas as direções - não mais o "redemunho" no meio da rua, repare-se, mas a perversão completa arrastando tudo consigo, o vórtice ou a voragem engolindo tudo e deixando a humanidade numa condição de intolerável aporia, ou seja, etimologicamente, numa condição em que "nem se tinha (não se tem, não se terá...) mais ruas".

Agentes dessa hipotética eversão, os catrumanos estão fora dela, estão fora de qualquer consciência de si e do mundo, estão fora de qualquer linguagem, estão fora de toda consideração ética ou política - eles são, enfim, esse fora que é, porém, o dentro mais interno e profundo do homem, representando, de fato, a natureza brutal e ferina, escondida "nos ocos" do sertão,

6 GS:V, p. 291.

7 GS:V, p. 295.

8 AGAMBEN, Giorgio. Stato di eccezione. Torino: Bollati Boringhieri, 2003. p. 56, passim.

9 SERRES, Michel. Genèse. Paris: Grasset, 1982. p. 112-13. 
num espaço atópico e intersticial, num tempo anterior ou posterior a todos os tempos.

0 jeito de estremecer, deles, às vezes, era todo, era de banda; mas aquilo sendo da natureza constante do corpo, e não temor - pois, quando pegavam receio, iam ficando era mais escuros, e respiravam com roncado rumor, quietos ali. Que aqueles homens, eu pensei: que nem mansas feras; isto é, que no comum tinham medo pessoal de tudo neste mundo. ${ }^{10}$

Como se sabe, a obra rosiana lida freqüentemente com essas situações extremas, com personagens ocupando aquele lugar mediano e "impossível" entre o humano e o desumano, que Heidegger definiu, a partir de Rilke ${ }^{11}$, como "o Aberto"12, mas aqui é nos dito - e não apenas representado, exposto na sua assombrosa evidência (como acontece, por exemplo, em "Meu tio o Iauaretê") -, aqui é tornado manifesto e posto em palavras todo o horror e o medo que eles suscitam: terror de um fundamento recalcado, de uma diferença que se percebe de modo confuso como o mais próprio do homem, como um lugar arquetípico e infernal pelo qual todos nós somos, a um tempo, convocados e repelidos ("mal-invocados", na sugestiva expressão de Riobaldo).

0 que mais digo: convém nunca a gente entrar no meio de pessoas muito diferentes da gente. Mesmo que maldade própria não tenham, eles estão com vida cerrada no costume de si, o senhor é de externos, no sutil o senhor sofre perigos. Tem muitos recantos de muita pele de gente. ${ }^{13}$

Não por acaso, em relação aos catrumanos, foi lembrada a imagem dos seringueiros da Amazônia desenhada por Euclides da Cunha ("um híbrido de demônio e truão, habitantes de um mundo perdido no passado" ${ }^{14}$ ). Também no romance de Rosa, de

10 GS:V, p. 292.

11 RILKE, Rainer Maria. Duineser Elegien. Frankfurt am Main: Insel Verlag, 1923. p. 48-53. Trad. it.: RILKE, Rainer Maria. Elegie duinesi. Torino: Einaudi, 1978.

12 AGAMBEN, Giorgio. L'aperto: l'uomo e l'animale. Torino: Bollati Boringhieri, 2002. p. 60-5.

$13 G S: V$, p. 294.

14 STARLING, Heloisa. Lembranças do Brasil: teoria, política, história e ficção em Grande Sertão: Veredas. Rio de Janeiro: Revan; UCAM/ IUPERJ, 1999. p. 157, nota. 
fato, aquilo que é descrito é uma categoria de pessoas habitando uma dimensão fronteiriça e ambígua, um território "à margem da história" ("nos tempos antigos, devia de ter sido assim"15): indivíduos, então, demorando numa história, de certo modo, póstuma, numa espécie de futuro do passado no qual vigora ainda um jogo extremo e sem regras, em que a aposta é a própria vida na sua biológica nudez e/ou na sua essência bio-política. Gente, então, sobrevivendo num estado de miséria absoluta, carentes de tudo e possuindo, dentro ou atrás da sua aparência ridícula ("rir, o que se ria"), apenas aquela força telúrica e abismal, aquele poder "mágico" ou demoníaco (khthónios, como diziam os gregos) que vem da sua natureza ancestral e tosca, do seu ser um limiar, uma margem anômica e inaccessivel a partir da qual, todavia, constitui-se uma história e institui-se uma comunidade - uma dimensão social, enfim, regida pelo Poder e pela Lei.

Porque, certamente, a pessoa que não tem nada apavora ("de homem que não possui nenhum poder nenhum, o senhor tenha medo!"16). Mas é só nessa total despossessão, é só nessa exclusão de qualquer tipo de autoridade que se tornam manifestos, por paradoxo, os mecanismos que regem as relações de Poder, os modos em que a Política se apodera, de forma autoritária, da existência individual no mundo moderno. E nessa perspectiva, é interessante notar a relação privilegiada e aparentemente inexplicável que se institui entre os catrumanos e Zé Bebelo: uma relação exclusiva e excludente, até o ponto em que, quando ele é destituído da chefia dos jagunços, alguns daquela "raça [...] diverseada distante" 17 pedem licença ao novo chefe, Urutu-Branco, para sair do bando e ele consente, raciocinando:

Ao que aqueles homens não eram meus de lei, eram de Zé Bebelo. E Zé Bebelo era assim instruído e inteligente, em salão de fazenda? Desisti, dado. Não baboseio. [...] Estúrdio é o que digo, nesta verdade - que, eu livre longe deles, desaluídos que eles estavam comigo; mas, eu quisesse com gana e préstimo deles, então só me serviam era na falsidade... 0 senhor me entende? E digo que eles eram homens tão diversos de mim, tão suportados nas coisas deles, que... por contar o que achei: que devia de ter pedido a eles a lembrança de muito rezarem por meu destino... ${ }^{18}$

15 GS:V, p. 290.

16 GS:V, p. 294.

17 GS:V, p. 294.

18 GS:V, p. 378. 
Os que se afastam não são, na verdade, os catrumanos do Pubo, mas os "dos Gerais, cabras do Alto-Urucúia. Os primeiros que com Zé Bebelo tinham vindo surgidos" ${ }^{19}$; sua natureza é todavia a mesma: também eles representam o mundo arcaico, escondido nos "ocos" do sertão, também eles habitam um tempo distante, ainda imbuído de um sentido mágico e religioso - tanto assim que eles parecem perceber a mudança de Riobaldo depois do pacto, querendo voltar ao Alto-Urucúia, e Riobaldo, por sua vez, suspeita que a defecção deles seja um sinal de "agouro", sentindo até vontade de pedir-lhes que rezem por seu "destino".

Mas creio que os elementos significativos sejam aqui, por um lado, a cumplicidade, a relação de submissão "legal” entre eles e Zé Bebelo ("não eram meus de lei, eram de Zé Bebelo"); e, por outro lado, a diferença que os separa de Riobaldo ("eles eram homens tão diversos de mim”). Interrogar a razão desta condição dupla significa, a meu ver, penetrar na estória até descobrir aquela história que ela, negando, reafirma. De fato, desde o início, é Zé Bebelo que trava contato com os catrumanos, é ele que os congrega com os outros jagunços - e isso pode parecer estranho, visto que este personagem é sempre apresentado como o portador de uma instância de modernidade e de legalidade, como o agente da ordem e do progresso no mundo arcaico dos sertões. 0 que tem ele a ver com os emblemas mais patentes do atraso, da miséria, da ignorância, da maldade e ilegalidade reinando no mundo sertanejo? Considero que a resposta é bastante fácil, se pensarmos que também ele, apesar de tudo, é uma espécie de figura liminar, ao mesmo tempo fora e dentro daquela realidade que atravessa, até como regente ou defensor dela. Como tem sublinhado Heloisa Starling ${ }^{20}$, para Zé Bebelo vale para sempre a sentença de Joca Ramiro: "O senhor não é do sertão. Não é da terra..." ${ }^{31}$ : dono da palavra requintada e astuciosa, defensor da lei do Estado e da sua Razão, ele, porém, está fora da sua pátria, fora da lógica antiga do sertão, fora do mito - é, enfim, um outsider, visto que a sua terra e o seu nómos são alhures, não conseguindo, por isso, alcançar nenhum dos seus objetivos:

De fato, em meio à sua perambulação sem fim, Zé Bebelo foi semeando ruínas, por onde passava, multiplicando sempre o

19 GS:V, p. 375.

20 STARLING, Heloisa. Lembranças do Brasil: teoria, política, história e ficção em Grande Sertão: Veredas. Rio de Janeiro: Revan; UCAM/ IUPERJ, 1999. p. 151.

21 GS:V, p. 199. 
mesmo gesto escorregadio, profundamente empenhado no esforço de construção do moderno apenas para se desmaterializar em seguida, e como que desvanecer na paisagem. ${ }^{22}$

Nessa perspectiva, penso que a relação privilegiada entre os catrumanos, agentes imaginários do Tumulto, produtores hipotéticos de Catástrofes, e este "semeador de ruínas" pode ser compreendida apenas naquele fora que os liga, naquela "plena e adversa exterioridade"23 em que se encontram - naquele Aberto ou naquele "estado de exceção", finalmente, em que permanecem suspensos.

De fato, já na bem conhecida resposta que Zé Bebelo dá à pergunta de um deles sobre a sua procedência, podemos ler esta dupla exclusão:

- "0 que mal não pergunto: donde será que ossenhor está servido de estando vindo, chefe cidadão, com tantos agregados e pertences?"

- "Ei, do Brasil, amigo!” - Zé Bebelo cantou resposta, alta graça. - "Vim departir alçada e foro: outra lei - em cada esconso, nas toesas deste sertão..."24

Se fica claro que os catrumanos não compartilham o mesmo espaço "legal” dos jagunços, também o chefe provisório destes parece, com sua resposta, colocar-se fora da lei sertaneja. Ou seja, ambos os interlocutores ficam numa situação de anomia em relação ao território que, apesar de tudo, ocupam: um, vindo duma distância e duma cronologia incomparáveis em relação ao tempo e ao espaço jagunços, chegando duma dimensão ligada à pólis e imediatamente política; os seus interlocutores, habitando um tempo fora da história e um espaço sem geografia - aqueles "ocos do sertão", aquela região que "se esconde em si mesma" (para utilizar ainda uma imagem que Euclides tira de John Milton, aplicando-a à Amazônia ${ }^{25}$ ). E de resto, já a resposta que Zé Bebelo tinha dado à acusação de Joca Ramiro de não

22 STARLING, Heloisa. Lembranças do Brasil: teoria, política, história e ficção em Grande Sertão: Veredas. Rio de Janeiro: Revan; UCAM/ IUPERJ, 1999. p. 156.

23 Ibid. p. 151.

24 GS:V, p. 293.

25 CUNHA, Euclides da. Um paraíso perdido: ensaios, estudos e pronunciamentos sobre a Amazônia. Org. por L. Tocantins. Rio de Janeiro: José Olympio; Fundação de Desenvolvimento de Recursos Humanos, da Cultura e do Desporto do Governo do Estado do Acre, 1986. p. 201. 
pertencer à terra parece bastante significativa: "Sou do fogo? Sou do ar? Da terra é a minhoca - que a galinha come e cata: esgaravata!"26: também ele, então, vive apenas no "rebuliço" (ele veio, de fato, para "rebolir com o sertão"), habita no tumulto ou no turbilhão que semeia ruínas, guardando sempre a sua identidade excepcional e, ao mesmo tempo, excetuada.

Sabe-se, aliás, que o estado de exceção é uma figura jurídica pela qual o Poder se vale do Direito para o suspender e se tornar assim "soberano". Como escreveu Giorgio Agamben:

se a exceção é a estrutura da soberania, a soberania não é, então, nem uma categoria exclusivamente jurídica, nem uma potência externa ao direito (Schmitt), nem a norma suprema do regimento jurídico (Kelsen): ela é a estrutura originária em que o direito se refere à vida e a inclui em si mesma através da sua própria suspensão. ${ }^{27}$

E o mesmo autor esclarece que a forma mais clara em que esta potência se exprime é o banimento:

aquele que é banido não é simplesmente colocado fora da lei e indiferente a ela, mas é abandonado por ela, isto é, é exposto e arriscado no limiar em que vida e direito, externo e interno se confundem. ${ }^{28}$

Sem querer aprofundar muito a análise desta figura ambígua e trágica do ordenamento político, posso porém chamar a atenção para o fato de que Zé Bebelo representa, no romance rosiano, um Poder externo e estranho ("Ei, do Brasil, amigo!") que usa a guerra e a violência - suspendendo, por isso, a sua "legitimidade" - para afirmar a sua soberania sobre um "mundo à revelia". Uma soberania, aliás, que se alia com o seu oposto aparente, com os que, no dizer de Riobaldo, não possuem "nenhum poder nenhum", vivendo numa condição de abandono completo e de total anomia.

Não por acaso, no romance se delineia um duplo movimento levando Zé Bebelo, "chefe cidadão", a "rebolir com o sertão como dono", e os catrumanos, na imaginação de Riobaldo, a

26 GS:V, p. 199.

27 AGAMBEN. Giorgio. Homo sacer: il potere sovrano e la nuda vita. Torino: Einaudi, 1995. p. 34.

28 Ibid., p. 34. 
"tomar conta das cidades": o encontro entre eles se dá, mais uma vez, naquele lugar banido e abandonado, dominado por uma lei bandida, que é o sertão - o Grande Sertão se confirmando, por isso, como espaço fronteiriço de uma luta e, ao mesmo tempo, de um compromisso absurdo entre o Direito e o seu oposto, entre o Poder soberano e a vida nua (para usar ainda uma expressão de Agamben, lembrando, por sua vez, outra de Benjamin). E as marcas desse pacto são, uma vez mais, as da exploração maldosa do Mal, do aproveitamento "político" daquela gente fora da história e da sociedade para fins que nada têm a ver com eles: instrumentos cegos e mudos de uma guerra que não lhes diz respeito, tendo como objetivo a hegemonia naquele Brasil que não lhes é Pátria, naquele País que é longe e que os "excetua", isto é, os "segura fora" (visto que o verbo excipio vem de ex capio - literalmente "tomo fora" - e mantém o duplo sentido de "recolher" e "excluir") na sua falta de tudo e no seu faltar a tudo.

Nesse sentido, a cena em que Tatarana tenta juntar os catrumanos ao bando dos "seus” jagunços é altamente significativa:

Aquela gente depunha que tão aturada de todas as pobrezas e desgraças. Haviam de vir, junto, à mansa força. Isso era perversidade? Mais longe de mim - que eu pretendia era retirar aqueles, todos, destorcidos de suas misérias. [...] Ah, os catrumanos iam de ser, de refrescos. Iam, que nem onças comedeiras! Não entendiam nada, assim atarantados, com temor ouviam minha decisão. ${ }^{29}$

Riobaldo, o pactário, quer usar para os seus fins a brutalidade daquela gente e se dá obscuramente conta da "perversidade" desse gesto assimilando, à "mansa força” jagunça, a violência fora de qualquer controle ou legitimidade dos catrumanos. Mesmo assim, permanece firme no seu propósito, escolhendo, porém, uma perspectiva diversa da de Zé Bebelo para associar aquela gente "estúrdia" ao seu intento hegemônico: não quer impor "outra lei”, mas valer-se deles - eles que estão fora de qualquer Direito, banidos e abandonados pelo Poder - na sua pessoal guerra ao mundo, no seu projeto "ilegal" de auto-afirmação, no seu desejo de glória:

Adivinhei a valia de maldade dêles: soube que eles me respeitavam, entendiam em mim uma visão gloriã. Não queriam ter cobiças? Homens sujos de suas peles e trabalhos. Eles não arcavam, feito criminosos? - "0 mundo, meus filhos, é longe 
daqui!" - eu defini. - Se queriam também vir? - perguntei. Ao vavar: o que era um dizer desseguido, conjunto, em que mal se entendia nada. Ah, esses melhor se sabiam se mudos sendo. ${ }^{30}$

Gente que não é gente (senão, repare-se, dentro e através da violência que a identifica na sua anomia e no seu anonimato, no seu ser turba); "raça diverseada distante" que não tem palavra, ou melhor, que só na sua mudez se torna compreensível; emblemas radicais, enfim, de uma corporeidade medonha e turbulenta, os catrumanos são a mão-de-obra barata e irrisória que o Poder inclui no seu discurso, no mesmo gesto que os exclui. Povo miserável e essencial, marginalizado e fundamental, carente e faminto, que se dispõe no limiar incerto entre Região e Nação, entre Sertão e Cidade, entre o Brasil e o Mundo, ficando longe dessas polaridades e, simultaneamente, preso dentro delas, na sua exceção e na sua intolerável evidência, que os torna alvo e agentes de uma força profundamente injusta, de uma soberania absoluta e sem piedade:

Aí foi que eu pensei o inferno feio deste mundo: que nele não se pode ver a força carregando nas costas a justiça, e o alto poder existindo só para os braços da maior bondade. ${ }^{31}$

Lugar continuamente aberto do degredo, espaço do banimento e do abandono, pátria, finalmente, de um direito bandido (jagunço), em que a lei vige apenas em sua própria suspensão ou em sua ambígua caricatura (como no julgamento de Zé Bebelo), o Grande Sertão se qualifica como a dimensão intermediária e de permuta, o limiar simbólico e real onde o Brasil e o Mundo se espelham na sua recíproca negação: instâncias tão próximas e tão longínquas das quais decorre um Poder autoritário que se aplica tão somente em seu ausentar-se, de uma Lei se manifestando apenas como força sem alvo ou tendo como único objetivo a sua pura e oca manutenção. Violência e Autoridade - confundidas na crítica da Gewalt (palavra mantendo justamente, em alemão, esses dois significados) proposta por Walter Benjamin - se articulam, por isso, numa zona vazia e medonha em que a lógica histórica é revogada: território baldio colocado nos confins do tempo e habitado apenas por homens debruçados sobre o abismo horroroso se abrindo entre o Ser e o Nada; por homens póstumos e excetuados, que vivem, enfim, nos "avessos" de qualquer humanidade.

Recebido em: Dez. 2006 Aprovado em: Jan. 2007

30 GS:V, p. 336.

31 GS:V, p. 295. 